\title{
新疆天山中段巴音布鲁克高山草地碳含量 及其垂直分布
}

\author{
安尼瓦尔 买买提 ${ }^{12}$ 杨元合 ${ }^{1}$ 郭兆迪 ${ }^{1}$ 方精云 ${ }^{1}$ \\ (1 北京大学环境学院生态学系, 北京大学地表过程分析与模拟教育部重点实验室 北京 100871) \\ (2 中国科学院新疆生态与地理研究所 乌鲁木齐 830011)
}

\begin{abstract}
摘 要 对新疆天山中段巴音布鲁克高山草地(高山草原和高山草甸)的生物量和土壤有机碳进行了测定。结果 表明积分和分层两种估算方法得到的土壤有机碳含量没有显著差异, 但积分算法的优势在于能推算不同深度的土 壤有机碳含量, 便于与以往的研究进行比较; 高山草甸的生物量和土壤有机碳含量均大于高山草原; 其地上生物量

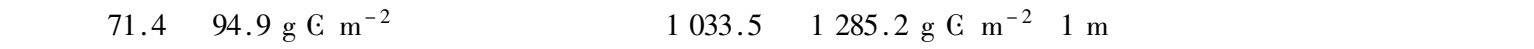
25.7 和 $38.8 \mathrm{~kg} \mathrm{~m}^{-2}$ 地上生物量呈现较为明显的垂直分布格局, 即随着海拔的增加 地上生物量先呈增加趋势, 但

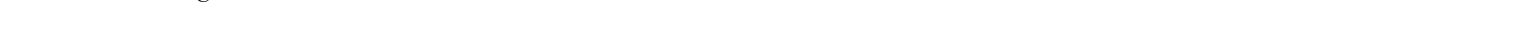
北坡(阴坡) 土壤有机碳含量还可能与地形、土壤质地等其它因素有关;两种高山草地(高山草原和高山草甸)的根 系集中分布在 $40 \mathrm{~cm}$ 以内 , $0 \sim 20 \mathrm{~cm}$ 根系分别占其总量的 76\% 和 $80 \%$ 汢壤有机碳集中分布在 $60 \mathrm{~cm}$ 以内, $0 \sim 20$ $\mathrm{cm}$ 土壤有机碳分别占其总量的 55\%和 49\% ; 高山草原根系分布比高山草甸深, 但较低的地下/地上比使得其有机 碳分布比高山草甸浅。
\end{abstract}

关键词 高山草原 高山草甸 生物量 土壤有机碳

\section{CARBON CONTENTS AND ITS VERTICAL DISTRIBUTION IN ALPINE GRASSLANDS IN BAYINBULAK , MIDDLE STRETCH OF THE TIANSHAN MOUTAINS OF XINJIANG}

\author{
MOHAMMAT Anwar $^{12}$ YANG Yuan-He ${ }^{1}$ GUO Zhao-Di ${ }^{1}$ and FANG Jing-Yun ${ }^{1}$ \\ (1 Department of Ecology, College of Environmental Sciences, and Key Laboratory for Earth Surface Processes of the \\ Ministry of Education, Peking University , Beijing 100871, China) \\ (2 Xinjiang Institute of Ecology and Geography , Chinese Academy of Sciences , Urumqi 830011 , China)
}

\begin{abstract}
Background and Aims Accurate estimates on the size of terrestrial organic carbon stocks are necessary for understanding their importance in regulating atmospheric $\mathrm{CO}_{2}$ concentrations. In this paper, biomass and SOC contents in alpine grasslands (alpine steppe and alpine meadow) in Bayinbulak were estimated. In addition, the vertical distribution of belowground carbon was discussed. Our objectives were to (a) estimate biomass and SOC contents of two different alpine grasslands , (b) investigate the root distribution of two alpine grasslands, and (c) explore the vertical distribution of SOC of two alpine grasslands.
\end{abstract}

Methods SOC content was estimated by an improved method (integral arithmetic method). Based on continuous decrease of SOC density with soil depth , integral arithmetic method could estimate SOC content to a given soil depth.

Key Results There were significant differences in the biomass between the alpine steppe and alpine meadow ; aboveground biomass of the alpine steppe was $71.4 \mathrm{~g} \mathrm{G} \mathrm{m}^{-2}$, whereas aboveground biomass of the alpine meadow was $94.9 \mathrm{~g} \mathrm{C} \mathrm{m}^{-2}$; belowground biomass of the two alpine grasslands was 1033.5 and 1285.2 $\mathrm{g} \mathrm{G} \mathrm{m}^{-2}$, respectively. No significant differences were found between integral arithmetic and traditional methods of estimating SOC contents. SOC contents of the alpine meadow was higher than in the alpine steppe ; SOC contents in the two alpine grasslands was 25.7 and $38.8 \mathrm{~kg} \mathrm{~m}^{-2}$, respectively. Most of the root biomass of the two alpine grasslands was in the upper $40 \mathrm{~cm}$ of the soil profile, while SOC was concentrated in the top 60 $\mathrm{cm}$. The two alpine grasslands had different root distributions ; the percentage of root biomass in the top $20 \mathrm{~cm}$ averaged $76 \%-80 \%$ for the alpine steppe and alpine meadow. Alpine meadows had a deeper root profile with 
only $49 \%$ of the SOC in the upper $20 \mathrm{~cm}$, whereas the alpine steppe had 55\% of the total SOC in the top 20 $\mathrm{cm}$.

Conclusions This study suggests that vegetation determines the vertical distribution of SOC through root : shoot ratio and its vertical root distribution.

Key words Alpine steppe , Alpine meadow , Biomass , Soil organic carbon

陆地生态系统碳库是估算陆地生态系统吸收和 排放含碳气体的关键要素(Valentini et al. ,2000)。 准确估算陆地生态系统碳库对于评估其碳通量大 小、预测全球气候变化具有重要意义(Garnett et al. , 2001)。地面观测 (Fang et al ., 2001 ; Pacala et al. , 2001 ; Goodale \& Davidson , 2002)和遥感估算 (Myneni et al.,2001)的结果一致表明 北半球中高纬度的陆 地生态系统是个重要的碳汇。作为陆地生态系统最 大的有机碳库, 土壤碳库的估算在全球 (Post et al. , 1982 ; Batjes , 1996)、国家 (Kern , 1994 ; Fang et al. , 1996 ; Wang et al.,2003; Wu et al.,2003) 和区域 ( Li \& Zhao, 2001) 尺度上都有开展。但是 地面观测 数据的缺乏和生态系统的异质性使得当前碳库估算 结果仍具有很大不确定性 (Garnett et al .,2001)。

根系是连接生态系统地上与地下过程的纽带 （Trumbore \& Grandinski，2003）,准确认识其垂直分布 对于理解和预测生态系统功能具有重要意义 ( Jackson et al. , 1996)。Jackson 等(1996) 利用已经发表 的 250 个根系研究结果, 对比了不同生物群区和不 同植被功能型根系的垂直分布。结果显示, 苔原、北 方森林和温带草地根系分布最浅, 而荒漠和温带针 叶林根系分布最深 搃体上, 全球 $10 、 20 、 40 \mathrm{~cm}$ 深的 根系分别占总根系的 $30 \% 、 50 \%$ 和 $75 \%$ 。随着地下 生态学的兴起 根系周转率、根系垂直分布格局等根 系参数的地理分异及其与控制因子 (如温度、降水、 土壤等)的关系已成为根系生物地理学的重要内容 (He et al. ,2004)。另一方面，土壤有机碳的垂直分 布已成为生态学家关注的问题 (Jobbágy \& Jackson , 2000)。Jobbágy 和 Jackson (2000) 利用 3 个全球土壤 数据库研究了土壤有机碳含量与气候、质地的关系, 验证了植被类型是土壤有机碳垂直分布控制因子的 假说。结果表明, 随着土壤深度的增加, 土壤有机碳 含量与气候的关系逐渐减弱, 而与质地的关系逐渐 增强, 灌丛、草原和森林 $0 \sim 20 \mathrm{~cm}$ 土壤有机碳分别 占其总量的 $33 \% 、 42 \%$ 和 $50 \%$, 即灌丛的有机碳分 布最深 草原次之, 森林最浅。

截止目前, 国内学者在植被碳库 (Fang et al. , 2001 ; Luo et al ., 2002 ; Li et al ., 2003 ; Ni , 2004 ; 朴世龙等, 2004 ; Zhou et al. , 2002) 和土壤碳库
(Fang et al., 1996 ; Li et al.,2003; 王绍强和周成 虎，1999; 王绍强等，2000，2003; Wang et al. , 2003 ; Wu et al. , 2003) 方面做了大量工作, 但对于 根系和土壤有机碳 (Wang et al. , 2004) 的垂直分布 研究甚少。位于天山腹地的巴音布鲁克草原是我国 仅次于鄂尔多斯的第二大草原(王恺等，2003) ,准 确估算其碳含量大小、了解其碳含量的垂直分布对 我国草地碳循环研究具有重要的科学意义。本文利 用实测的生物量和土壤有机碳数据, 试图揭示: 1) 积分和分层两种方法估算的土壤有机碳含量的差 异，2)该地区两种草地类型 (高山草原、高山草甸)的 碳含量是否存在差异 3) 两种草地类型的根系垂直 分布有何区别 ;A) 两种草地类型的土壤有机碳垂直 分布如何。

\section{1 材料和方法}

\section{1 研究区域概况}

本研究于 2004 年 $7 \sim 8$ 月在中国科学院新疆生 态与地理研究所巴音布鲁克草原生态系统定位研究 站进行。地处 $42^{\circ} 54^{\prime} \mathrm{N}, 83^{\circ} 43^{\prime} \mathrm{E}$, 天山中段大尤尔 都斯盆地。气候属典型的高寒气候, 冷季漫长 暖季 短暂, 年均温 $-4.8{ }^{\circ} \mathrm{C}, 1$ 月最低温可达 $-48{ }^{\circ} \mathrm{C} ; 7$ 月 最高温可达 $30.5{ }^{\circ} \mathrm{C}$; 年降水量约 $276.2 \mathrm{~mm}$, 年蒸发 量高达 $1022.9 \sim 1247.5 \mathrm{~mm}$, 全年积雪日达 $150 \sim$ $180 \mathrm{~d}$, 无绝对无霜期。植被类型多样, 主要包括高 山沼泽草甸、亚高山草原、亚高山草甸化草原、亚高 山草原化草甸、亚高山草甸、高山草甸;相应的土壤 类型为高山沼泽土、亚高山草原土、亚高山草甸化草 原土、亚高山草原化草甸土、亚高山草甸土、高山草 甸土(叶尔道来提等, 1989)。

\section{2 野外采样}

自盆地底部(海拔 $2460 \mathrm{~m}$ ) 向两面山坡, 海拔每 升高 $100 \mathrm{~m}$ 设置 1 个样地, 直至草甸的分布上限(海 拔 $3470 \mathrm{~m}$ ) 共设置 20 个样地。在每个样地, 设置 1 个大样方 $(10 \mathrm{~m} \times 10 \mathrm{~m})$, 在大样方四角及中心部位 各设置 1 个小样方 $(1 \mathrm{~m} \times 1 \mathrm{~m})$, 共计 5 个, 调查每 个小样方内出现的物种及其高度、盖度, 并记录样地 经纬度、海拔、坡度和坡向等。将 5 个小样方内植物 地上部分全部剪下,除去粘附的土壤、砾石等杂质后 
全部带回实验室分析。每个样地挖 1 个土壤剖面， 利用环刀分层 $(0 \sim 10 、 10 \sim 20 、 20 \sim 30 、 30 \sim 40 、 40 \sim$ $50 、 50 \sim 60 \mathrm{~cm}$ )采集用于测定容重的土样, 同时分层 采集用于分析有机碳的土样。此外,在每处样地设 置 1 个小样方 $(20 \mathrm{~cm} \times 20 \mathrm{~cm})$, 用于测定地下生物 量。将地上部分齐地面刚割后, 每 $10 \mathrm{~cm}$ 为 1 层采 集地下生物量 共取 6 层 将带根的土块在河水中浸 泡 $1 \sim 2 \mathrm{~d}$, 然后将其放置于 100 目土壤筛中用水冲 洗。

\section{3 室内分析}

地上生物量在 $65{ }^{\circ} \mathrm{C}$ 条件下烘干至恒重 将野外 处理过的根系在实验室内再次冲洗 然后在 $65{ }^{\circ} \mathrm{C}$ 条 件下烘干至恒重。在 $105{ }^{\circ} \mathrm{C}$ 条件下土样烘干至恒 重, 并测定容重和其中 > $2 \mathrm{~mm}$ 的砾石含量 ;用于测 定有机碳浓度的风干土样, 四分法取样后挑去其中 $>2 \mathrm{~mm}$ 的砾石, 并使其全部通过 $2 \mathrm{~mm}$ 土壤篮, 然 后挑去其中的根系, 最后利用 Retsch S100 球磨机粉 碎, 并使其全部通过 100 目土壤篩。采用重铬酸钾 外加热氧化法测定土壤有机质浓度, 同时测定土壤 含水率 (鲍士旦等, 2000)。

\section{4 数据处理}

\section{4 .1 生物量}

5 个小样方地上生物量求平均得到每个样地的 地上生物量。在此基础上计算得到两种草地类型 (高山草原、高山草甸) 的地上生物量平均值和标准 误。同时 利用样地的地下生物量计算得到两种草 地类型的地下生物量平均值和标准误。本文使用转 换系数 $(0.45)$ 将生物量统一以碳 $\left(\mathrm{g} \mathrm{C} \mathrm{m}^{-2}\right)$ 的形式 表示。

\section{4 .2 土壤有机碳}

考虑到土壤有机碳含量随深度的垂直变化 (Jobbágy \& Jackson，2000)，采用积分方法计算了每 个土壤剖面的有机碳含量 $\left(\mathrm{kg} \mathrm{G} \mathrm{m}^{-2}\right)$ 。首先计算每 层的有机碳含量 $\left(\mathrm{g} \mathrm{cm}^{-3}\right)$ (公式 1$)$, 在此基础上建 立有机碳含量与深度的函数关系, 并积分计算整个 剖面的有机碳含量(式 2)。

$$
S O C D_{i}=0.58 \times \rho_{i} \times M_{i} \times\left(1-C_{i}\right) / 10
$$

式中, 0.58 为 Bemmelen 系数 (将有机质浓度转化为 有机碳浓度) , $\rho_{i}, M_{i}, C_{i}$ 分别表示第 $i$ 层土壤容重 $\left(\mathrm{g} \mathrm{cm}^{-3}\right)$ 、有机质密度 $(\%) 、>2 \mathrm{~mm}$ 的砾石含量 $(\%), S O C D_{i}$ 为第 $i$ 层土壤有机碳含量 $\left(\mathrm{g} \mathrm{cm}^{-3}\right)$ 。

$$
S O C C=\iint_{n_{i-1}}^{h_{i}} \operatorname{SOCD}(h) d(h)\left(h_{i}-1\right)
$$

式中, $h$ 表示土壤深度 $(\mathrm{cm}), S O C D(h)$ 为土壤有机 碳含量与深度的函数关系, $S O C C$ 为土壤有机碳含
量 $\left(\mathrm{kg} \mathrm{m}^{-2}\right)$ 。

为了和传统的分层算法比较, 我们还采用分层 方法计算了每个土壤剖面的有机碳含量(公式 3 )。

$$
S O C C=\sum_{i=1}^{n} 0.58 \times T_{i} \times \rho_{i} \times M_{i} \times\left(1-C_{i}\right) / 10
$$

式中, $n$ 为剖面层数, 0.58 为 Bemmelen 系数(将有机 质含量转化为有机碳含量 $N, T_{i}, \rho_{i}, M_{i}, C_{i}$ 分别表 示第 $i$ 层土层厚度 $(\mathrm{cm})$ 、土壤容重 $\left(\mathrm{g} \mathrm{cm}^{-3}\right)$ 、有机质 含量 $(\%) 、>2 \mathrm{~mm}$ 的砾石含量 $(\%), S O C C$ 为土壤有 机碳含量 $\left(\mathrm{kg} \mathrm{m}^{-2}\right)(\mathrm{Wu}$ et al. , 2003)。

\subsection{3 根系和土壤有机碳的垂直分布}

建立根系生物量与深度的函数关系,用于推算 不同深度的根系生物量。为了定量表述根系和土壤 有机碳的垂直分布情况, 将土壤剖面划分为 $0 \sim 20$ 、 $20 \sim 40 、 40 \sim 60 、 60 \sim 80 、 80 \sim 100 \mathrm{~cm} 5$ 个层次, 并分 别计算每层的根系生物量和土壤有机碳。同时, 采 用 $0 \sim 20 \mathrm{~cm}$ 的根系生物量和土壤有机碳分别占其 总量 ( $1 \mathrm{~m}$ 深度) 的百分比来表示根系和土壤有机碳 的垂直分布, 即 $0 \sim 20 \mathrm{~cm}$ 占的比例越高, 意味着根 系或土壤有机碳分布越浅 ;反之越深。

\section{2 结果与分析}

\section{1 不同方法估算的土壤有机碳含量差异}

土壤有机碳含量不仅是统计土壤有机碳储量的 重要参数, 也是反映土壤特性的重要指标(金峰等, 2001)。为了比较分层和积分两种土壤有机碳含量 计算方法的差异，我们给出了分层和积分的土壤有 机碳含量计算结果 (图1)。从图中可以看出, 两种

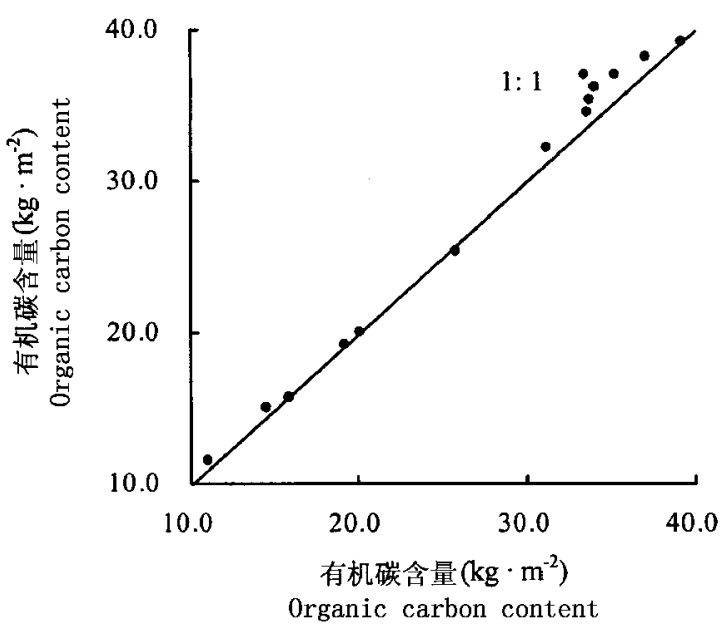

图 1 分层和积分计算的土壤有机碳含量

Fig. 1 Soil organic carbon content calculated by two methods 横轴为分层方法计算的有机碳含量，纵轴为积分方法计算的有 机碳含量 Horizontal axis : organic carbon content calculated by layered method, vertical axis : organic carbon content calculated by integral method 
算法得到的土壤有机碳含量没有显著差异。传统的 分层算法将土壤剖面划分为若干层次, 并分别计算 各层的土壤有机碳含量, 最后求和得到整个剖面的 土壤有机碳含量( Wu et al. , 2003)。分层算法由于 没有考虑到土壤有机碳含量随深度的垂直变化, 无 法估算特定深度的土壤有机碳含量 相反地 积分算 法基于土壤有机碳含量和土壤深度的函数关系, 能 够估算任意深度的土壤有机碳含量。在积分算法 中，一些学者主张分别建立土壤有机碳浓度和土壤 容重与土壤深度的函数关系 (金峰等, 2001) ,也有 学者倾向于直接建立土壤有机碳含量与土壤深度的 函数关系 (Jobbágy \& Jackson，2000)。一方面, 土壤 容重与深度的函数关系往往并不显著; 另一方面, 曲 线拟合存在残差,减少拟合次数可以提高估算精度。 鉴于上述原因, 我们直接建立了土壤碳含量与土壤 深度的函数关系,并利用积分算法估算了土壤有机 碳含量。分层和积分算法的对比表明, 两种方法得 到的土壤有机碳含量没有显著差异 (图 1)。但积分 算法的优势在于能推算不同深度的土壤有机碳含 量, 便于与以往的研究进行比较 其不足之处在于少 数剖面土壤有机碳含量与深度的函数关系不显著，

\section{只能分层计算。}

\section{2 不同草地类型碳含量的差异}

表 1 给出了样地水平的生物量 (地上、地下) 和 土壤有机碳含量 $(0 \sim 60 \mathrm{~cm})$ 。为了和其它研究结果 对比，我们利用积分算法还计算了表层 $(0 \sim 30 \mathrm{~cm})$ 和 $1 \mathrm{~m}$ 深度的土壤有机碳含量 (表 1 )。从表中可以 看出 地上生物量最大的是位于盆地底部的高山沼 泽草甸(143.4 $\mathrm{g} \mathrm{C} \mathrm{m}^{-2}$ ), 最小的是分布在南坡(阳 坡)的亚高山草甸 $\left(47.2 \mathrm{~g} \mathrm{G} \mathrm{m}^{-2}\right)$ 。地下生物量最 大的是位于盆地底部的高山沼泽草甸 (2 107.1 g C $\mathrm{m}^{-2}$ ) , 最小的是分布在南坡 (阳坡)的亚高山草原化 草甸 $\left(752.6 \mathrm{~g} \mathrm{C} \mathrm{m}^{-2}\right)$ 。土壤碳含量 $(0 \sim 100 \mathrm{~cm})$ 最 大的是位于阳坡的亚高山草甸 $\left(50.2 \mathrm{~kg} \mathrm{~m}^{-2}\right)$,最小 的是位于阳坡的亚高山草原 $\left(11.8 \mathrm{~kg} \mathrm{~m}^{-2}\right)$ 。图 2 给出了地上生物量随海拔的变化趋势。从图 2 中可 以看出 地上生物量呈现较为明显的垂直分布格局， 即随着海拔的增加，地上生物量呈增加趋势，但是， 海拔超过一定界限后生物量突然下降。为了解释不 同样地土壤有机碳含量的空间分异, 我们分析了土 壤有机碳含量与土壤含水率的关系(图 3)。从图 3 中可以看出,南坡(阳坡)土壤有机碳含量与其含水

表 1 巴音布鲁克高山草地生物量和土壤有机碳含量

Table 1 Biomass and soil organic carbon content of alpine grassland in Bayinbulak

\begin{tabular}{|c|c|c|c|c|c|c|c|c|}
\hline \multirow{2}{*}{$\begin{array}{l}\text { 样地号 } \\
\text { Plot No. }\end{array}$} & \multirow{2}{*}{$\begin{array}{l}\text { 海拔 (m) } \\
\text { Altitude }\end{array}$} & \multirow{2}{*}{$\begin{array}{l}\text { 坡向 } \\
\text { Aspect }\end{array}$} & \multirow{2}{*}{$\begin{array}{c}\text { 群落类型 } \\
\text { Community type }\end{array}$} & \multicolumn{2}{|c|}{$\begin{array}{c}\text { 生物量 } \\
\text { Biomass }\left(\mathrm{g} \mathrm{C} \mathrm{m} \mathrm{m}^{-2}\right)\end{array}$} & \multicolumn{3}{|c|}{$\begin{array}{c}\text { 土壤有机碳含量 }\left(\mathrm{kg} \mathrm{m}^{-2}\right) \\
\text { Soil organic carbon content }\end{array}$} \\
\hline & & & & $\begin{array}{l}\text { 地上 } \\
\text { Shoot }\end{array}$ & $\begin{array}{l}\text { 地下 } \\
\text { Root }\end{array}$ & $0 \sim 30 \mathrm{~cm}$ & $0 \sim 60 \mathrm{~cm}$ & $0 \sim 100 \mathrm{~cm}$ \\
\hline $\mathrm{P} 1$ & 2470 & 无 No & 亚高山草原4) & 58.1 & 871.3 & 13.5 & 19.2 & 22.1 \\
\hline $\mathrm{P} 2$ & 2570 & 阳坡 ${ }^{1)}$ & 亚高山草原4) & 60.4 & 1006.6 & 12.3 & 15.0 & 15.7 \\
\hline P3 & 2670 & 阳坡1) & 亚高山草原4) & 65.6 & 1020.7 & 9.7 & 11.4 & 11.8 \\
\hline P4 & 2770 & 阳坡 ${ }^{1)}$ & 亚高山草原 ${ }^{4)}$ & 70.3 & 893.2 & 12.0 & 15.7 & 16.7 \\
\hline P5 & 2870 & 阳坡 ${ }^{1)}$ & 亚高山草原4) & 74.2 & 777.4 & 9.8 & 12.1 & \\
\hline P6 & 2970 & 阳坡 ${ }^{1)}$ & 亚高山草甸化草原5) & 81.7 & 1737.6 & 29.0 & 37.0 & 39.5 \\
\hline P7 & 3070 & 阳坡 ${ }^{1)}$ & 亚高山草甸 ${ }^{6)}$ & 89.4 & 1369.6 & 27.1 & 40.3 & 50.2 \\
\hline P8 & 3170 & 阳坡1) & 亚高山草甸6) & 99.7 & 1060.2 & 26.3 & 35.3 & 37.7 \\
\hline P9 & 3270 & 阳坡 ${ }^{1)}$ & 亚高山草甸6) & 107.1 & 1172.8 & 21.8 & 32.1 & 39.4 \\
\hline P10 & 3370 & 阳坡1) & 亚高山草甸 ${ }^{6)}$ & 81.6 & 1265.4 & 16.5 & 26.7 & \\
\hline P11 & 3470 & 阳坡 ${ }^{1)}$ & 亚高山草甸 ${ }^{6)}$ & 75.6 & 1009.5 & 15.8 & 20.0 & 21.3 \\
\hline P12 & 2570 & 阴坡 ${ }^{2)}$ & 亚高山草甸化草原5) & 89.7 & 928.0 & 25.4 & 38.3 & 48.4 \\
\hline P13 & 2670 & 阴坡 ${ }^{2)}$ & 亚高山草原化草甸7) & 97.3 & 1274.2 & 19.7 & 28.3 & \\
\hline P14 & 2770 & 半阴坡 ${ }^{3)}$ & 亚高山草原化草甸7) & 94.8 & 752.6 & 30.6 & 35.1 & 36.1 \\
\hline P15 & 2870 & 半阴坡 ${ }^{3)}$ & 高山草甸 ${ }^{8)}$ & 105.5 & 1273.5 & 24.2 & 37.0 & 47.5 \\
\hline P16 & 2970 & 半阴坡 ${ }^{3)}$ & 高山草甸 ${ }^{8)}$ & 118.4 & 1531.1 & 19.1 & 25.4 & 27.7 \\
\hline P17 & 3070 & 半阴坡 ${ }^{3)}$ & 高山草甸 ${ }^{8)}$ & 123.9 & 1724.6 & 19.9 & 32.7 & \\
\hline P18 & 3170 & 阴坡 ${ }^{2)}$ & 亚高山草甸 ${ }^{6)}$ & 49.5 & 1289.9 & 27.1 & 39.2 & 45.6 \\
\hline P19 & 3270 & 阴坡 ${ }^{2)}$ & 亚高山草甸6) & 47.2 & 876.5 & 22.8 & 34.6 & 44.0 \\
\hline $\mathrm{P} 20$ & 2460 & 无 No & 高山沼泽草甸 ${ }^{9)}$ & 143.4 & 2107.1 & 17.7 & 28.2 & \\
\hline
\end{tabular}

1) Sun slope 2) Shade slope 3) Semi-shade slope 4) Subalpine steppe 5) Subalpine meadow steppe 6) Subalpine meadow 7) Subalpine steppe meadow 8) Alpine meadow 9) Alpine swamp meadow 


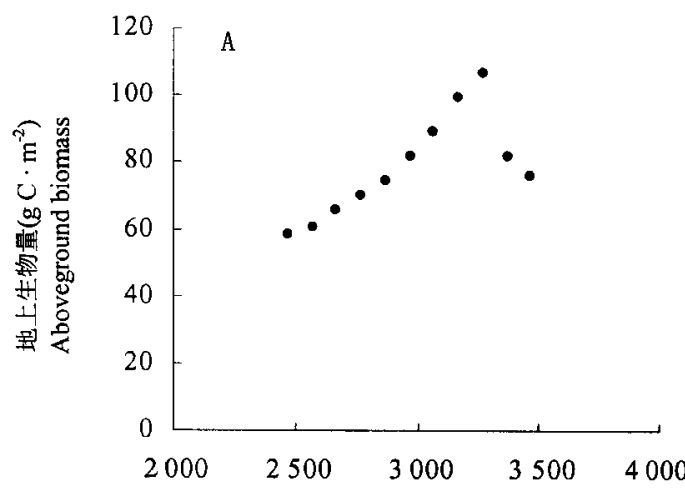

海拔 Altitude (m)

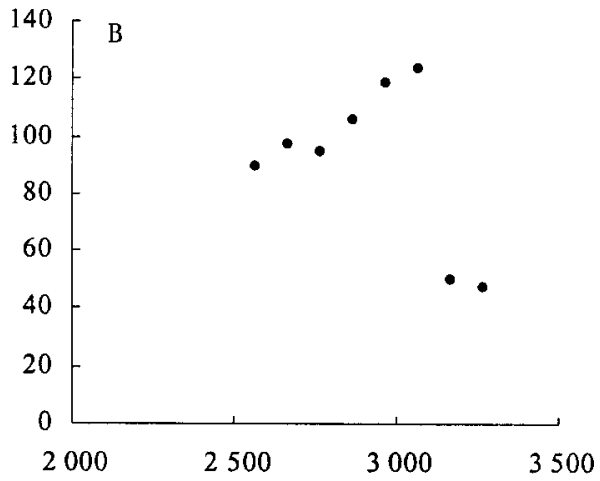

海拔 Altitude (m)

图 2 地上生物量沿海拔梯度的变化

Fig.2 Changes in aboveground biomass along an altitudinal gradient A : 南坡 Southern slope B : 北坡 Northern slope
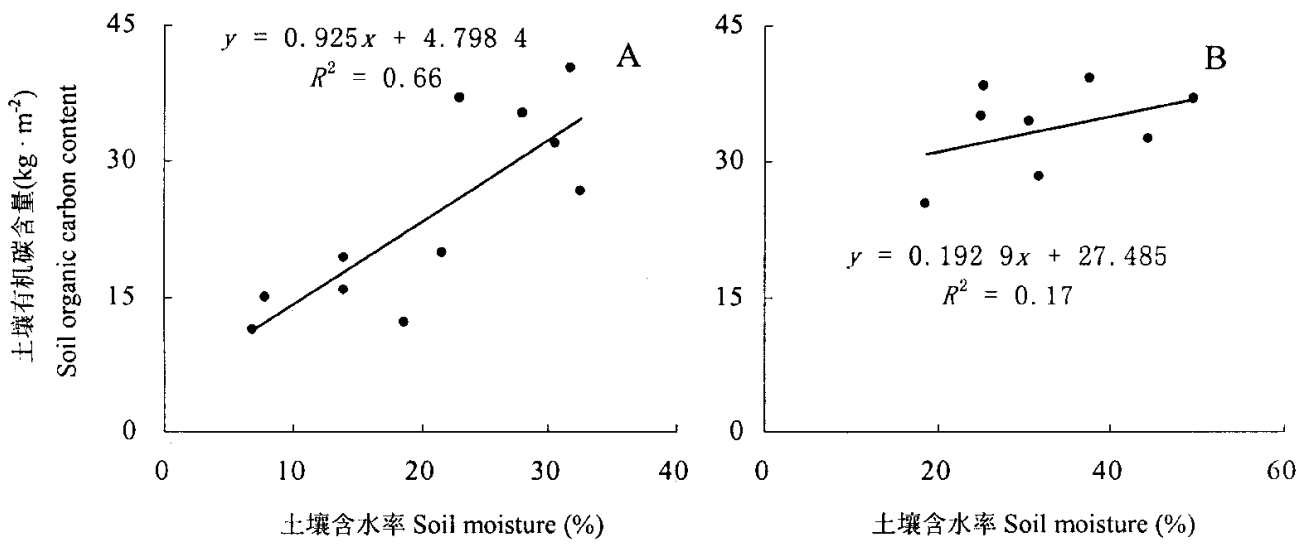

图 3 土壤有机碳含量与土壤含水率的关系

Fig.3 Relationship between soil organic carbon content and soil moisture A ,B :同图 2 See Fig.2

率显著正相关, 土壤含水率能解释南坡(阳坡)土壤 有机碳含量变异的 $66 \%$ 。这意味着水分条件是导 致南坡(阳坡)土壤有机碳含量空间差异的重要因 素。然而，土壤含水率仅能解释北坡(阴坡) 土壤有 机碳含量变异的 $17 \%$,这意味着北坡(阴坡) 土壤有 机碳含量还可能与地形、土壤质地等其它因素有关。

为了比较不同草地类型生物量和土壤有机碳含 量的差异，我们将 20 个样地划分为两种草地类型 (高山草原、高山草甸)，并分别计算了每种类型的生 物量和土壤有机碳含量 (图 4)。从图中可以看出, 高山草甸的生物量和土壤有机碳含量均大于高山草 原。两种高山草地的地上生物量分别为: 高山草原 $\left(71.4 \mathrm{~g} \mathrm{G} \mathrm{m}^{-2}\right)$ 、高山草甸 $\left(94.9 \mathrm{~g} \mathrm{C} \mathrm{m}^{-2}\right)$ 均高于 全国草地地上生物量平均值 $\left(44.1 \mathrm{~g} \mathrm{G} \mathrm{m}^{-2}\right.$ ) (朴世 龙等，2004）这意味着高山草地在我国草地植被中
占有重要地位。两种高山草地的地下生物量分别 为: 高山草原为 $1033.5 \mathrm{~g} \mathrm{C}^{-2}$ 、高山草甸为 $1285.2 \mathrm{~g} \mathrm{C} \mathrm{m}^{-2}$ 。李英年等(2003)曾报道小嵩草高 寒草甸、矮嵩草高寒草甸地下生物量分别为 819.5、 $928.6 \mathrm{~g} \mathrm{G} \mathrm{m}^{-2}$ 。可以看出, 我们的结果与李英年等 (2003)的结果是可以比较的。两种高山草地的土壤 有机碳含量 $(0 \sim 100 \mathrm{~cm})$ 分别为: 高山草原 $(25.7 \mathrm{~kg}$ $\mathrm{m}^{-2}$ )、高山草甸 $\left(38.8 \mathrm{~kg} \mathrm{~m}^{-2}\right)$ 均高于全国土壤有 机碳含量的平均水平 (高山草原土 : $7.5 \mathrm{~kg} \mathrm{~m}^{-2}$; 高 山草甸土 : $9.5 \mathrm{~kg} \mathrm{~m}^{-2}$ )(Wu et al.,2003)。Garnett 等(2001) 在已经发表的 NPP 数据基础上,结合部 分实测资料估算了英国沼泽生态系统碳库, 并检验 了基于清查资料估算的碳库准确性。结果显示, 利 用实测数据与基于清查资料估算的植被碳库接近， 但土壤碳库相差较大。我们的结果显示, 巴音布鲁 
克高山草地土壤有机碳含量显著高于全国平均值。 若用全国平均值来估算巴音布鲁克高山草地土壤有 机碳库, 势必会产生很大误差。此外，第二次全国土 壤普查采样量不够大、分布不均匀 (尤其是西部地 区)使得当前土壤碳库的估算仍具有很大不确定性。
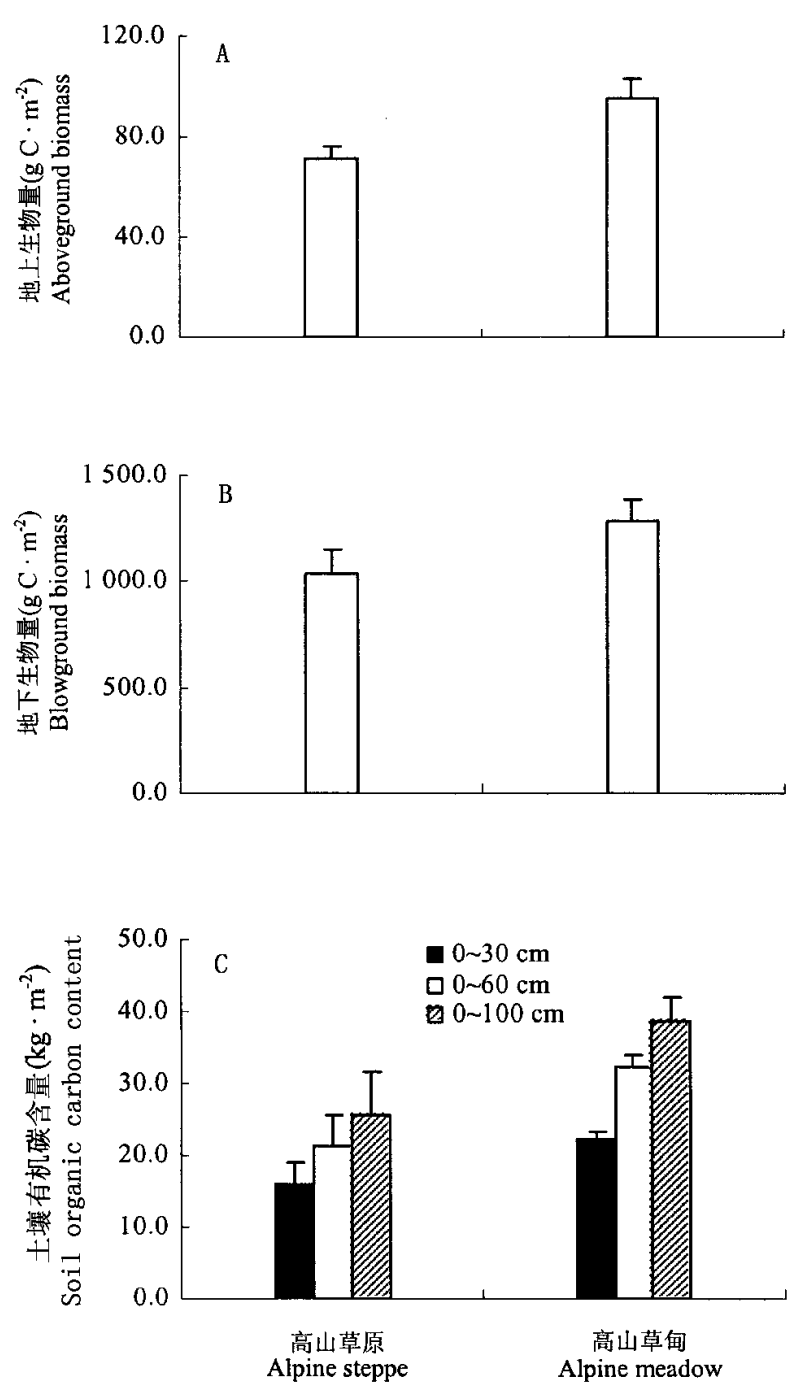

图 4 巴音布鲁克高山草地地上生物量、地下生物量 和土壤有机碳含量

Fig.4 Aboveground biomass, belowground biomass and soil organic carbon content of alpine grassland in Bayinbulak

2.3 不同草地类型根系和土壤有机碳的垂直分布

图 5 给出了两种高山草地 (高山草原、高山草 甸)根系和土壤有机碳的垂直分布。从图中可以看 出, 高山草原 0 20 cm 根系占其总量的 76\%, 0 40 $\mathrm{cm}$ 根系占其总量的 93\%; 高山草甸 $0 \sim 20 \mathrm{~cm}$ 根系 占其总量的 $80 \%, 0 \sim 40 \mathrm{~cm}$ 根系占其总量的 $92 \%$ 。 可以看出, 高山草地的根系集中分布在 $40 \mathrm{~cm}$ 以上; 并且, 高山草原的根系比高山草甸分布更深。高山
草原 $0 \sim 20 \mathrm{~cm}$ 土壤有机碳占其总量的 $55 \%, 0 \sim 60$ $\mathrm{cm}$ 土壤有机碳占其总量的 $90 \%$; 高山草甸 $0 \sim 20 \mathrm{~cm}$ 土壤有机碳占其总量的 $49 \%, 0 \sim 60 \mathrm{~cm}$ 土壤有机碳 占其总量的 $87 \%$ 。这意味着两种高山草地的有机 碳集中分布在 $60 \mathrm{~cm}$ 以上; 并且, 高山草甸的有机碳 比高山草原分布更深。上述结果表明, 两种草地类 型根系和土壤有机碳的垂直分布不同, 并且根系比 土壤有机碳分布更浅, 这与 Jackson 等 (1996)、 Jobbágy 和 Jackson (2000) 在全球尺度上得出的结论 一致。根系的垂直分布受植物生活型、气候以及土 壤的控制(Schenk \& Jackson，2002)。高山草原比高 山草甸根系分布更深(图 5), 这与 Schenk 和 Jackson (2002) 在全球尺度上得到的结果一致。Schenk 和 Jackson(2002) 在全球尺度上的研究显示, 沿着水分 梯度，从草甸、普列利草原(Prairie)到半干旱草原，根 系分布越来越深。植被类型是土壤有机碳垂直分布 的控制因子 根系垂直分布和地下/地上比的差异决 定了土壤有机碳垂直分布的差异 ( Jobbágy \& Jackson, 2000)。虽然高山草原根系比高山草甸分布更 深，但其有机碳却比高山草甸分布更浅(图 5)。已 有的研究表明, 高山草原的地下/地上比 (4.25) 小于 高山草甸(7.92)(李文华和周兴民，1998)。不难理 解，尽管高山草原根系分布更深，但较低的地下/地 上比使其有机碳分布较浅。我们的结果还显示, 两 种草地类型根系比土壤有机碳分布更浅, 这与 Jobbágy 和 Jackson (2000) 在全球尺度上得到的结果 一致。导致根系比土壤有机碳分布更浅的可能原因 有: : ) 有机碳周转率随深度增加而下降, 使得深层有 机碳积累 2) 淋溶作用使得表层有机碳向下转移 3) 土壤有机体的垂直混合作用使得表层有机碳在下层 富集( Jobbágy \& Jackson，2000)。

\section{3 结 论}

通过对新疆天山中段巴音布鲁克高山草地生物 量和土壤有机碳含量的研究, 得出如下结论:

1) 基于样地水平的生物量分析表明, 随着海拔 的增加 地上生物量呈增加趋势。但是 海拔超过一 定界限后生物量突然下降。基于样地水平的土壤有 机碳含量分析表明, 土壤含水率能解释南坡 (阳坡) 土壤有机碳含量变异的 $66 \%$ 。这意味着水分条件 是导致南坡(阳坡)土壤有机碳含量空间差异的重要 因素。然而, 土壤含水率仅能解释北坡 (阴坡) 土壤 有机碳含量变异的 $17 \%$,这意味着北坡(阴坡) 土壤 有机碳含量还可能与地形、土壤质地等其它因素有 

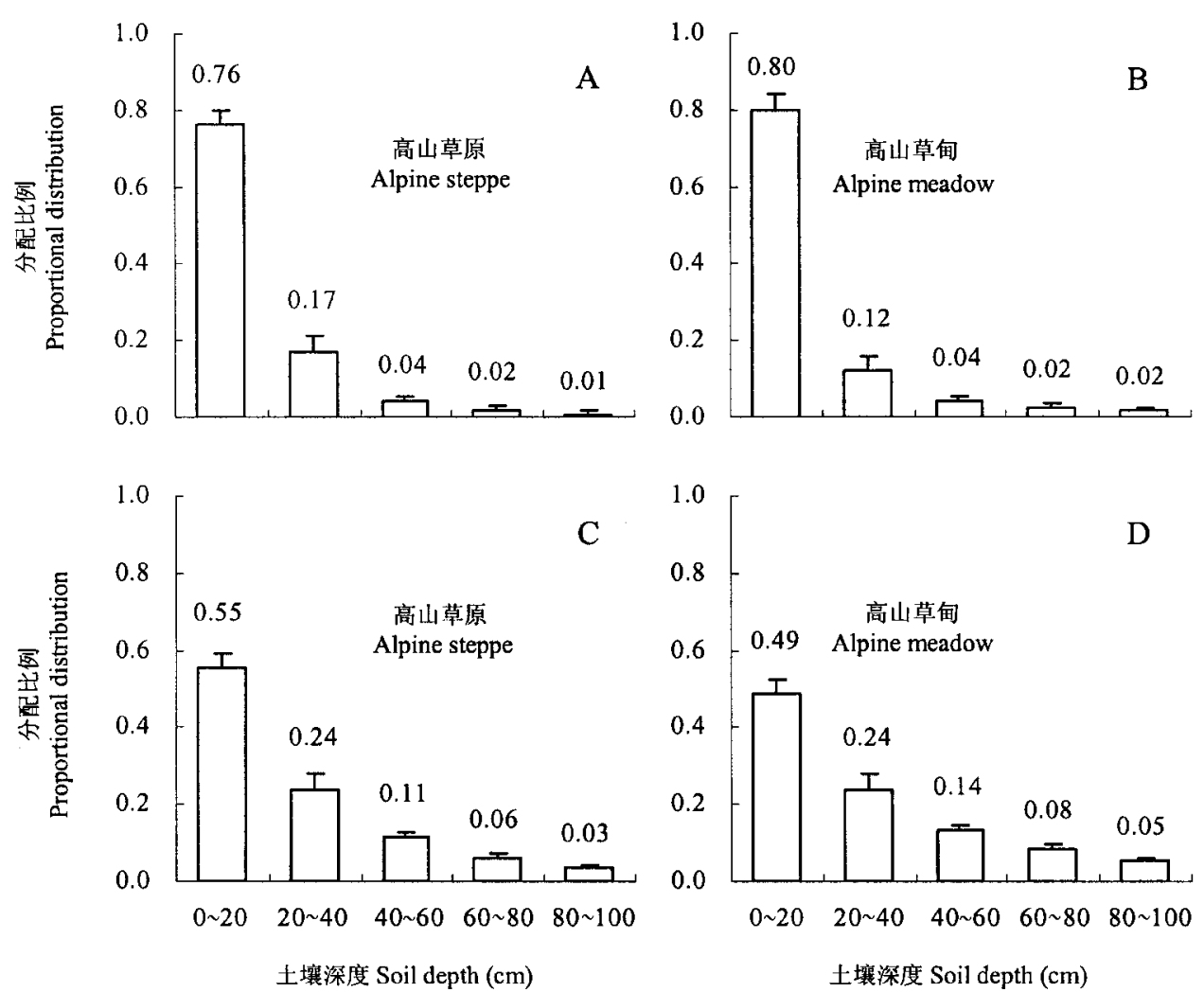

图 5 巴音布鲁克高山草地根系 $(A 、 B)$ 和土壤有机碳 $(C 、 D)$ 的垂直分布

Fig.5 Vertical distribution of root (A, B) and soil organic carbon (C, D) of alpine grassland in Bayinbulak

关。

2) 基于草地类型的生物量和土壤有机碳含量 分析表明, 高山草甸的生物量和土壤有机碳含量均 大于高山草原。两种高山草地的地上生物量分别 是: 高山草原为 $71.4 \mathrm{~g} \mathrm{Ci} \mathrm{m}^{-2}$ 、高山草甸为 94.9 $\mathrm{g} \mathrm{G} \mathrm{m}^{-2}$ 。两种高山草地的地下生物量分别为: 高山 草原为 $1033.5 \mathrm{~g} \mathrm{C}^{-2}$ 、高山草甸为 1285.2 $\mathrm{g} \mathrm{G} \mathrm{m}^{-2}$ 。积分和分层两种估算方法得到的土壤有 机碳含量没有显著差异;两种高山草地(高山草原、 高山草甸) $1 \mathrm{~m}$ 深度的土壤有机碳含量分别为 25.7 、 $38.8 \mathrm{~kg} \mathrm{~m}^{-2}$ 。

3) 两种高山草地(高山草原、高山草甸)的根系 集中分布在 $40 \mathrm{~cm}$ 以内 ,土壤有机碳集中分布在 60 $\mathrm{cm}$ 以内; $0 \sim 20 \mathrm{~cm}$ 根系分别占其总量的 $76 \%$ 和 $80 \%, 0 \sim 20 \mathrm{~cm}$ 土壤有机碳分别占其总量的 $55 \%$ 和 49\%。高山草原比高山草甸根系分布更深, 这与 Schenk 和 Jackson(2002) 在全球尺度上得出的结论一 致。尽管高山草原根系分布更深, 但较低的地下/地 上比使其有机碳分布较浅。此外,两种草地类型根 系比土壤有机碳分布更浅, 这与 Jobbágy 和 Jackson (2000) 在全球尺度上得到的结果一致。

\section{参 考 文 献}

Bao $\mathrm{SD}$ (鲍士旦), Jiang $\mathrm{RF}$ (江荣风), Yang $\mathrm{CG}$ (杨超光), $\mathrm{Xu}$ GH(徐国华)，Han XR(韩晓日) (2000). Soil and Agricultural Chemistry Analysis (土壤农化分析). China Agriculture Press, Beijing. (in Chinese)

Batjes NH (1996). Total carbon and nitrogen in the soils of the world. European Journal of Soil Science, 47, 151 - 163.

Erdawlat (叶尔道来提), Merey (麦来), Adil (阿得勒) (1989). Analysis on environmental condition and suitable utilization of grassland in Bayinbulak. Arid Zone Research (干旱区研 究), 6(Suppl. ), 5-21. (in Chinese)

Fang JY, Chen AP, Peng CH, Zhao SQ, Ci LJ (2001). Changes in forest biomass carbon density in China between 1949 and 1998. Science, 292, $2320-2322$.

Fang JY, Liu GH, Xu SL (1996) . Soil carbon pool in China and its global significance. Journal of Environmental Sciences, 8, 249 -254 .

Garnett MH, Ineson P, Stevenson AC, Howard DC (2001). Terrestrial organic carbon density in a British moorland. Global Change Biology, 7, 375 - 388 .

Goodale CL, Davidson EA (2002). Uncertain sinks in the shrubs. Nature, 418, $593-594$.

He JS, Wang ZQ, Fang JY (2004). Issues and prospects of belowground ecology with special reference to global climate change. 
Chinese Science Bulletin, 49, 1891 - 1899.

Jackson RB, Canadell J, Ehleringer JR, Mooney HA, Sala OE, Schulze ED (1996). A global analysis of root distributions for terrestrial biomes. Oecologia, 108, 389-411.

Jin F (金峰), Yang H (杨浩), Cai ZC (蔡祖聪), Zhao QG (赵 其国) (2001). Calculation of density and reserve of organic carbon in soils. Acta Pedologica Sinica (土壤学报), 8, 522 528. (in Chinese with English abstract)

Jobbágy EG, Jackson RB (2000). The vertical distribution of soil organic carbon and its relation to climate and vegetation. Ecological Applications, 10, 423 - 436 .

Kern JS (1994). Spatial patterns of soil organic carbon in the contiguous United States. Soil Science Society of America Journal, $59,1134-1141$.

Li KR, Wang SQ, Cao MK (2003). Vegetation and soil carbon density in China. Science in China, Series D, 33, $72-80$.

Li WH (李文华), Zhou XM (周兴民) (1998). Ecosystems of Qinghai-Xizang(Tibetan) Plateau and Approach for Their Sustainable Management (青藏高原生态系统及优化利用模式). Guangdong Science \& Technology Press, Guangzhou. (in Chinese)

Li YN (李英年), Zhao XQ (赵新全), Wang QX (王勤学), Gu $\mathrm{S}$ (古松), Du MY (杜明远), Tomomichi K (加藤知道), Wang QL (王启兰), Zhao L (赵亮) (2003). The comparison of community biomass and environmental condition of five vegetation types in alpine meadow of Haibei, Qinghai Province. Journal of Mountain Science (山地学报), 21, 257-264. (in Chinese with English abstract)

Li Z, Zhao QG (2001). Organic carbon content and distribution in soils under different land uses in tropical and subtropical China. Plant and Soil, 231, $175-185$.

Luo TX, Li WH, Zhu HZ (2002) . Estimated biomass and productivity of natural vegetation on the Tibetan Plateau. Ecological Applications, 12, $980-997$.

Myneni RB, Dong J, Tucker CJ, Kaufmann RK, Kauppi PE, Liski J, Zhou L, Alexeyev V, Hughes MK (2001). A large carbon sink in the woody biomass of Northern forests. Proceedings of the National Academy of Sciences of the United States of America, 98, 14784 - 14789.

Ni J (2004) . Forage yield-based carbon density in grasslands of China. Climatic Change, 67, $237-246$.

Pacala SW, Hurtt GC, Baker D, Peylin P, Houghton RA, Birdsey RA, Heath L, Sundquist ET, Stallard RF, Ciais P, Moorcroft P, Caspersen JP, Shevliakova E, Moore B, Kohlmaier G, Holland E, Gloor M, Harmon ME, Fan SM, Sarmiento JL, Goodale CL, Schimel D, Field CB (2001). Consistent land- and atmosphere-based U.S. carbon sink estimates. Science, 292, $2316-$ 2320 .

Piao SL (朴世龙), Fang JY (方精云), He JS (贺金生), Xiao
Y (肖玉) (2004). Spatial distribution of grassland biomass in China. Acta Phytoecologica Sinica (植物生态学报), 28, 491 - 498. (in Chinese with English abstract)

Post WM, Emanuel WR, Zinke PJ, Stangenberger AG (1982). Soil carbon pools and world life zones. Nature, 298, 156- 159. Schenk HJ, Jackson RB (2002). The biogeography of roots. Ecological Monographs, 72, $311-328$.

Trumbore SE, Grandinski JB (2003). The secret lives of roots. Science, 302, $1344-1345$.

Valentini R, Matteucci G, Dolman AJ, Schulze ED, Rebmann C, Moors EJ, Granier A, Gross P, Jensen NO, Pilegaard K, Lindroth A, Grelle A, Bernhofer C, Grunwald T, Aubinet M, Ceulemans R, Kowalski AS, Vesala T, Rannik U, Berbigier P, Loustau D, Guomundsson J, Thorgeirsson H, Ibrom A, Morgenstern K, Clement R, Moncrieff J, Montagnani L, Minerbi S, Jarvis PG (2000). Respiration as the main determinant of carbon balance in European forests. Nature, 404, 861 - 865 .

Wang K (王恺), Ma JZ(马建章), Zhang GL(张观礼), Liu YK (刘玉凯), Song CS(宋朝枢) (2003). National Nature Reserve in China (中国国家级自然保护区). Anhui Science \& Technology Press, Hefei. (in Chinese)

Wang SQ (王绍强), Liu JY (刘纪远), Yu GR (于贵瑞) (2003) . Error analysis of estimating terrestrial soil organic carbon density in China. Chinese Journal of Applied Ecology (应用生态 学报), 14, 797 - 802. (in Chinese with English abstract)

Wang SQ (王绍强), Zhou CH (周成虎) (1999). Estimating soil carbon reservoir of terrestrial ecosystem in China. Geographical Research (地理研究), 18, 349-356. (in Chinese with English abstract)

Wang SQ (王绍强), Zhou CH (周成虎), Li KR (李克让), Zhu SL (朱松丽), Huang FH (黄方红) (2000). Analysis on spatial distribution characteristics of soil organic carbon reservoir in China. Acta Geographica Sinica (地理学报), 55, 533 544. (in Chinese with English abstract)

Wang SQ, Huang M, Shao XM, Mickler RA, Li KR, Ji JJ (2004). Vertical distribution of soil organic carbon in China. Environmental Management, 33 (Suppl.), doi: 10. 1007/ s00267-003-9130-5.

Wang SQ, Tian HQ, Liu JY, Pan SF (2003). Pattern and change of soil organic carbon density in China: 1960s - 1980s. Tellus, 55B, $416-427$.

Wu HB, Guo ZT, Peng CH (2003) . Distribution and storage of soil organic carbon in China. Global Biogeochemical Cycles, 17, doi: 10. 1029/2001GB001844.

Zhou GS, Wang YH, Jiang YL, Yang ZY (2002). Estimating biomass and net primary production from forest inventory data: a case study of China's Larix forests. Forest Ecology and Management, $169,149-157$. 